\title{
Effect of Carbon Nanofiber-Matrix Adhesion on Polymeric Nanocomposite Properties-Part II
}

\author{
Khalid Lafdi, William Fox, Matthew Matzek, and Emel Yildiz \\ University of Dayton, 300 College Park, Dayton, OH 45469, USA
}

Received 22 March 2007; Accepted 5 July 2007

Recommended by Donglu Shi

\begin{abstract}
A successful integration of two independent phases with good adhesion is imperative for effective translation of superior carbon nanofiber filler properties into a physically superior carbon nanocomposite. Carbon nanofibers were subjected to electrochemical oxidation in $0.1 \mathrm{M}$ nitric acid for varying times. The strength of adhesion between the nanofiber and an epoxy matrix was characterized by flexural strength and modulus. The surface functional groups formed and their concentration of nanofibers showed a dependence on the degree of oxidation. The addition of chemical functional groups on the nanofiber surface allows them to physically and chemically adhere to the continuous resin matrix. The chemical interaction with the continuous epoxy matrix results in the creation of an interphase region. The ability to chemically and physically interact with the epoxy region is beneficial to the mechanical properties of a carbon nanocomposite. A tailored degree of surface functionalization was found to increase adhesion to the matrix and increase flexural modulus.
\end{abstract}

Copyright (c) 2008 Khalid Lafdi et al. This is an open access article distributed under the Creative Commons Attribution License, which permits unrestricted use, distribution, and reproduction in any medium, provided the original work is properly cited.

\section{INTRODUCTION}

Research on vapor-grown carbon nanofibers (VGCFs) has been heightened in recent years by the discovery of carbon nanotubes. Such fibers are characterized by an extraordinarily high tensile modulus, tensile strength, and high electrical and thermal conductivity. A decrease in the diameter of a vapor-grown carbon nanofiber causes gradual improvement in mechanical properties. As the fiber diameter reaches the threshold value of $1 \mu \mathrm{m}$, distinguishing the transition from a fiber to a nanofiber, the improvement in mechanical properties becomes more significant [1]. Vapor-grown carbon nanofibers can be prepared with diameters ranging from $15 \mathrm{~nm}$ to $100 \mathrm{~nm}$. These fibers are not continuous and have hollow cores. Their morphology resembles that of carbon nanotubes. Nanofibers can have a number of different internal structures, wherein graphene layers are arranged as concentric cylinders, nested truncated cones, segmented structures, or stacked coins [2]. External morphologies include kinked and branched structures and diameter variation. The percolation threshold for carbon nanofibers is low indicating that only a small amount of nanofiber additive is required for conducting filler applications. The intrinsic stiffness and strength of carbon nanofibers, combined with these superior transport properties, present the opportunity to develop multifunctional nanofiber composites with tailored physical and mechanical properties.

Experimental results from previously published research efforts indicate that VGCFs are suitable reinforcing agents for polymers. Lozano and Barrera demonstrated a $100 \%$ increase in the dynamic mechanical properties with $2 \mathrm{wt} \%$ VGCF in a polypropylene matrix [3]. Other work by Kuriger et al. with a higher loading of VGCFs in polypropylene produced over a $50 \%$ increase in tensile strength [4]. Patton et al. combined VGCFs with an epoxy and poly (phenylene sulfide) to improve the flexural properties of the matrix materials. They obtained 68 and $91 \%$ increases in the flexural strength in epoxy and poly (phenylene sulfide), respectively, with a nominal fiber loading of $20 \%$ by volume [5].

Fiber functionalization is considered necessary to improve mechanical properties in nanofiber-reinforced composites by increasing the stress transfer between the nanofiber and the matrix of a nanocomposite structure. Fiber-matrix adhesion is governed by the chemical and physical interactions at the interface. Extensive literature exists on surface treatment of conventional carbon fibers by methods such as oxidation in gas and liquid phases and anodic etching. Poor fiber-matrix adhesion may result in composite failure at the interface, resulting in decreased longitudinal and transverse mechanical properties of the composite. 
Surface modification of carbon nanofibers changes the graphitization extent of the fiber and increases its surface area of the fiber. Lim et al. studied "stacked coin"-type nanofibers and the impact of mechanical and chemical treatments on the morphology of the fibers [6]. Heat treatment at $2800{ }^{\circ} \mathrm{C}$ induced closed loop ends on the surface of the nanofibers formed by folding of some planar hexagons at their edges. The heat treatment removed $\mathrm{C}-\mathrm{H}$ bonds and densely stacked hexagonal layers of graphene, forming chemically active sites on the edges. The edges were stabilized by bonding to each other, even though the bonding caused high tension through the formation of a sharp curvature. Acidic oxidation of the nanofibers cuts off the closed looped ends, resulting in improved overall alignment of graphene layers. Both treatments generated many free edges and a high graphitization extent, indicating the possibility of improved interfacial bonding with a polymer matrix.

Toebes et al. [7] examined the effect of liquid phase oxidation of carbon nanofibers in nitric acid and mixtures of nitric and sulfuric acid for times up to two hours. The graphitic structure of the nanofibers was not altered by the treatments, but the texture of the fibers were significantly changed through increase in the specific surface area and pore volume due to the opening of the fiber inner tubes. The total oxygen content and surface oxygen functional groups were affected by the treatment time and acid type. Oxygen groups were also formed in the first 2-3 nm of the subsurface of the fibers.

Bubert et al. [8] investigated the influence of plasma treatment on the surface properties of carbon nanofibers by X-ray photoelectron spectroscopy (XPS) in combination with ion sputtering, acid-base titration, derivatization of carbonyl groups, pyrolysis, and $\mathrm{CH}$ analysis. The results indicated that the fiber surface is covered by a monomolecular oxygen-containing layer and that plasma treatment allows complete oxygen functionalization of the uppermost surface layer. XPS provides an average value for the content of functional groups of the first ten to fifteen molecular layers.

A number of results have been reported on the effect of chemical modification of carbon nanotubes on nanocomposite properties. Xu et al. included a nitric acid-oxidized nanofiber/vinyl ester composite in an examination of electrical properties of nanocomposites [9]. The resistivity of the oxidized fiber nanocomposites were much higher than that of those produced with untreated fibers. The oxidation was reported to have increased oxygen percentage by approximately $20 \%$ with the addition of anhydride, quinine, ether, and ester functional groups. The oxidized layer could reduce conductivity through percolation pathways. The functional groups should also improve wetting by the polymer matrix. A strong bond between matrix and fiber could encase the fiber and serve as an insulating covering.

Finegan et al. [10] examined the mechanical properties of carbon nanofiber/polypropylene composites in an attempt to optimize carbon nanofiber surface treatment. The fibermatrix adhesion was qualitatively studied by scanning electron microscopy (SEM), and the strength and stiffness of the composites were evaluated from tensile tests. One sample of nanofibers was oxidized in air at $450{ }^{\circ} \mathrm{C}$ and a second sam- ple was oxidized with carbon dioxide in a tube furnace. Fiber matrix adhesion was improved by moderately oxidizing the fibers in either air or carbon dioxide. The carbon dioxide oxidation was more effective as it increased the external surface area and the surface energy of the fibers. However in the preparation of the nanocomposites, the fibers were either ball milled or force sieved, thereby possibly altering the fiber aspect ratios resulting in decreased mechanical testing results.

Cortes et al. [11] exposed carbon nanofibers to a series of chemical treatments in nitric acid prior to mixing with polypropylene. The oxidized fiber nanocomposites did not improve electrical properties of the polymer, did not produce significant changes in the mechanical properties of the composites, and showed a decrease in tensile strength. The nanocomposites had only produced $5 \mathrm{wt} \%$ VGCF compositions. Higher fiber content may have led to increases in the mechanical properties of the composites.

In conventional carbon fiber-reinforced composites, there have been a number of studies completed to generate strong adhesion between the fiber surface and matrix to improve stress transfer from the matrix to the reinforcing fibers. Continuous surface electrochemical oxidation has been the preferred method of fiber surface treatment to enhance interfacial bonding. Electrochemical treatments have been carried out in acid and alkaline aqueous solutions of ammonium sulfate, ammonium bicarbonate, sodium hydroxide, diammonium hydrogen phosphate, and nitric acid.

Anodic oxidation of fibers in electrolytes can produce a variety of chemical and physical changes in the fiber surface. Harvey et al. [12] examined surfaces of conventional carbon fibers by XPS after electrochemical treatment by galvanostatic and potentiostatic cell control under varying potential, reaction time, and electrolytes. They noted that the rise in interlaminar shear strength (ILSS) with surface treatment is not dependent on O-1s:C-1s ratios or the amount of carboxyl functionality on the surface, thereby supporting the view that mechanical keying of the resin to the fiber surface plays an important role in forming the resin-fiber bond.

Gulyas et al. [13] subjected PAN-based carbon fibers to electrochemical oxidation under a wide variety of conditions - varying electrolyte, electrolyte concentration, and applied voltage. The functional groups formed on the surface of the fibers were dependent on the type of electrolyte used, and the number of functional groups found on the fiber surface was dependent on electrolyte concentration and voltage. A close correlation was found between surface chemistry and fiber/matrix adhesion. The concentration of certain functional groups could be quantitatively related to ILSS.

Yue et al. [14] applied continuous electrochemical oxidation to high-strength PAN-based carbon fibers in $1 \%$ by weight potassium nitrate. Fiber weight loss increased with electrochemical oxidation. A large internal micro porous surface area was generated due to the formation of acidic functions. XPS indicated that the concentration of oxygen within the outer $50 \AA$ of the fibers increased on oxidation. XPS C$1 \mathrm{~s}$ and $\mathrm{O}-1 \mathrm{~s}$ spectra showed an increase in primarily carboxyl or lactone groups. The oxygen-rich surfaces in the micro porous regions chemisorbed oxygen and water. The 
$\mathrm{O}-2 \mathrm{~s}-\mathrm{C}-2 \mathrm{~s}$ peak separation increased in the valence band spectra as the extent of oxidation increased due to carbonyl group contribution.

In this study, vapor-grown carbon nanofibers were subjected to electrochemical oxidation in $0.1 \mathrm{M}$ nitric acid for varying times to modify the interface between the nanofibers and epoxide molecules in epoxide/nanofiber composites. Xray photoelectron spectroscopy was employed to characterize surfaces with regard to the content of carbon, oxygen, and nitrogen. The strength of adhesion between the fiber and an epoxy (thermoset) matrix was characterized by the tensile strength and modulus, and the electrical and thermal properties of the composites were investigated from the viewpoint of surface treatment of carbon nanofibers.

\section{EXPERIMENTAL SETUP AND PROPERTY MEASUREMENT}

The carbon nanofibers used in this study were produced at Applied Sciences, Inc. (Detriot, MI, USA) and were from the Pyrograf III ${ }^{\mathrm{TM}}$ family of fibers. This group of nanofibers (labeled PR-24) has diameters between 60 and 100 un and lengths ranging from 30 to $100 \mu \mathrm{m}$. The nanofibers were electrochemically surface treated using nitric acid as an electrolyte in a concentration of $1 \mathrm{wt} \%$. Approximately $15 \mathrm{~g}$ of nanofibers for each trial were packed into covered, porous plastic beakers and submerged in the acidic solution. Previous studies have shown that an amount of $12 \%$ by weight added to epoxy polymer has led to maximum mechanical performance. We chose a graphite electrode submerged into the packed nanofibers, and a specific applied current was set at 0.1 amps. The time of the treatments was 30 seconds, 1 minute, 2 minutes, 4 minutes, 8 minutes, and 15 minutes. Following treatment, the oxidized fibers were washed with distilled water until attaining a neutral $\mathrm{pH}$ and dried in a vacuum oven at $100^{\circ} \mathrm{C}$ for 48 hours.

The functionalized carbon nanofibers were characterized using X-ray photoelectron spectroscopy (XPS). The samples were oriented such that the axial direction was in the plane of the X-ray source and the analyzer detection slit. During all XPS experiments, the pressure inside the vacuum system was maintained at approximately 1 torr. A nonlinear least squares curve fitting program with a Gaussian-Lorentzian mix function and background subtraction was used to deconvolve the XPS peaks.

While investigation of surface chemistry was performed by XPS using chemical shift phenomena, in several cases, relative chemical shifts of different groups are below the energy resolution attainable by XP spectrometers due to the existence of significant intrinsic peak widths. In these cases, other sample properties, like chemical reactivity, could operate the requested discrimination. Chemical derivatization XPS (CDXPS), based on selective reaction labeling groups of interest, was used to improve the selectivity and sensitivity of the XPS analysis. The methodology has been applied mainly to organic polymers, even though some inorganic materials have also been studied. Derivatization reactions have been established for $\mathrm{C}-\mathrm{OH}, \mathrm{COOH}, \mathrm{C}=\mathrm{O}$, and $\mathrm{C}-\mathrm{NH}_{2}$ groups. Infor- mation obtained by the simple XPS evidence of the marker element must be complemented by careful analysis of the main signals, to which both the organic material and the derivatizing agent contribute. This procedure will determine whether each reaction occurs according to the expected stoichiometry.

$\mathrm{C}-\mathrm{OH}$ groups can be esterified by trifluoroacetic anhydride (TFAA). A procedure for the derivatization of a polymer sample calls for the sample to be introduced into a glass test tube. two mL of TFAA were injected into the test tube below the sample, without contacting it. The test tube was sealed, and the reaction with the TFAA vapor was allowed to proceed for 15 minutes at room temperature. The sample was then removed from the test tube, and transferred to the $\mathrm{XP}$ spectrometer for analysis.

Derivatizing the sample with TFAA vapor results in the conversion of the phenol substituent to a trifluoroester group. This leads to the appearance of new peaks at 290.4 and $293.7 \mathrm{eV}$ which are attributed to the ester and $\mathrm{CF}_{3}$ carbon atoms, respectively. The peak area of the trifluoroacetic ester $\left(\mathrm{CF}_{3} \mathrm{COO}\right)$ component is used for a quantitative estimate for the $\mathrm{C}-\mathrm{OH}$ groups by calculating one third of the $\mathrm{F} 1 \mathrm{~s}$ area. TFAA labels virtually all of the hydroxyl groups within the XPS sampling depth.

$\mathrm{COOH}$ groups can be esterified by trifluoroethanol (TFE) vapors, making use of di-t-butyl carbodiimide (DtC) as a dehydrating agent. A procedure for the derivatization of a polymer sample calls for the sample to be suspended in a glass test tube; TFE $(0.9 \mathrm{~mL})$, pyridine $(0.4 \mathrm{~mL})$, and DtC $(0.3 \mathrm{~mL})$ were sequentially injected below the sample, without contacting it, at 15 minutes intervals. The test tube was sealed with a cap and the reaction was allowed to proceed at room temperature for 12 hours. The samples were then transferred to the XP spectrometer and analyzed.

An assumption of the reaction is that the reaction product of DtC $\left(N, N^{\prime}\right.$-di-( $t$-butyl)-urea) is completely removed from the surface of the reacted organic material, though no washing stage is performed. This behavior has been confirmed in literature. The reaction has been shown to yield about $99 \%$ esterification of the $\mathrm{COOH}$ groups by TFE. Esterification by TFE causes three fluorine atoms to be introduced into the sample for each $\mathrm{COOH}$ group. An enhancement of the response factor should be obtained and the XPS detectability of this functionality then improved. One source of error could be due to the presence of ionized $\mathrm{COOH}$ groups, which are not susceptible to esterification mediated by carbodiimides.

The carbon nanofibers were added to an epoxy resin matrix (EPON 862) forming a nanocomposite. Since bulk nanofibers are difficult to incorporate into resin matrices, the nanofibers were first dispersed in the epoxy resin. The resulting mixture was cured under pressure in a silicone mold.

The mechanical properties of the nanocomposites were measured using the three-point bending test according to ASTM D790-00. The specimen size was 3.0 in (length) by 0.5 in (width), with the depth dependent upon the composite sample. The three-point bend test had a span ratio (span-to-depth of sample) of $16: 1$. This value is suggested 
TABLE 1: Atomic percentages of nanofibers as a function of electrochemical treatment time.

\begin{tabular}{lcc}
\hline Sample & Oxygen \% & Carbon \% \\
\hline As-received & 2.0 & 98.0 \\
30 s treatment & 2.3 & 97.7 \\
1 min treatment & 2.8 & 97.2 \\
2 min treatment & 3.5 & 96.5 \\
4 min treatment & 4.2 & 95.8 \\
8 min treatment & 5.4 & 94.6 \\
10 min treatment & 7.6 & 92.4 \\
12 min treatment & 8.3 & 91.7 \\
15 min treatment & 8.6 & 91.4 \\
\hline
\end{tabular}

by ASTM D790-00 for materials with a depth greater than $0.0625 \mathrm{in}$.

The thermal conductivity of each nanocomposite incorporated a xenon flash diffusivity test. The procedure is outlined in ASTM C714-72, with the test specimens cut to 0.5 in (length) by 0.5 in (width) by 0.03 in (depth). Thermal diffusivity is calculated according to the equation $\alpha=$ $0.139 L^{2} / t_{1 / 2}$, where $L$ is the thickness of the sample and $t_{1 / 2}$ is the time at which the rear surface of the test specimen reaches one half its maximum temperature. The thermal diffusivity parameter is used in conjunction with the specific heat and density of the nanocomposite to calculate the thermal conductivity. The tests for specific heat and density were carried out according to ASTM E1269-89 and ASTM C693-74, respectively. Thermal conductivity is calculated according to the equation $K=C_{p} \rho \alpha$, where $C_{p}$ is the specific heat of the sample and $\rho$ is the density of the sample.

The electrical properties of the carbon nanocomposites were studied utilizing a four-point test according to ASTM B 193-87. The two outer leads of the tester are connected to the current source and the two inner leads are used to measure the voltage drop through the nanocomposite. Ohm's law, equation 6 , allows for the resistance of the sample to be determined. By coupling the calculated resistance with the known cross-sectional area and distance between leads, the resistivity $\rho$ of the sample can be deduced

\section{RESULTS AND DISCUSSION}

Surface characterization of the nanofibers by XPS (see Table 1) showed an increase in oxygen content from $2 \%$ in the as-received fibers to $8.6 \%$ in the fibers treated for fifteen minutes. The $\mathrm{N}$ 1s peak was negligible in all cases.

Deconvolution of the $\mathrm{C} 1 \mathrm{~s}$ spectra (see Table 2) gives the potential for five peaks: graphitic carbon $(284.6 \mathrm{eV})$, carbon present in phenolic, alcohol, ether, or $\mathrm{C}=\mathrm{N}$ groups $(286.1-$ $286.3 \mathrm{eV})$, carbonyl or quinone groups $(287.3-287.6 \mathrm{eV})$, carboxyl or ester groups $(288.4-288.9 \mathrm{eV})$, and carbonate (290.4-290.8 eV). Figure 2 shows the calculated percentage of graphitic and functional carbon atoms. There is a significant decrease in the relative content of graphitic carbon (peak I) and a rise in the relative content of carbon bonded
TABLE 2: Calculated percentages of graphitic and functional carbon atoms.

\begin{tabular}{lccccc}
\hline Sample & I & II & III & IV & V \\
\hline 30 s treatment & 90 & 6 & 4 & 0 & 0 \\
1 min treatment & 87 & 13 & 0 & 0 & 0 \\
2 min treatment & 86 & 7 & 2 & 2 & 3 \\
4 min treatment & 80 & 14 & 6 & 0 & 0 \\
8 min treatment & 78 & 9 & 6 & 4 & 3 \\
10 min treatment & 79 & 11 & 9 & 0 & 0 \\
12 min treatment & 75 & 21 & 4 & 0 & 0 \\
15 min treatment & 74 & 23 & 2 & 0 & 0 \\
\hline
\end{tabular}

TABLE 3: Calculated percentages of oxygen-containing groups.

\begin{tabular}{lccc}
\hline Sample & I & II & III \\
\hline 30 s treatment & 57 & 43 & 0 \\
1 min treatment & 67 & 33 & 0 \\
2 min treatment & 70 & 22 & 8 \\
4 min treatment & 75 & 20 & 5 \\
8 min treatment & 78 & 22 & 0 \\
10 min treatment & 81 & 19 & 0 \\
12 min treatment & 83 & 17 & 0 \\
15 min treatment & 84 & 16 & 0 \\
\hline
\end{tabular}

to oxygen-containing functions (peaks II, III, IV, and V) with increasing amount of electrochemical treatment. The increase in relative concentration of carbon oxygen complexes occurs because the outer layers of the fibers become increasingly porous. The fraction of carbon atoms in the region which exists on the pore surfaces increases. These carbon atoms are the sights of oxidation, thereby increasing the relative amount of oxygen.

Table 3 shows the deconvolution of the $\mathrm{O} 1$ s spectra fitted to three component peaks: $\mathrm{C}=\mathrm{O}$ groups including ketone, lactone, carbonyl $(531.2-531.6 \mathrm{eV}), \mathrm{C}-\mathrm{OH}$ and $\mathrm{C}-\mathrm{O}-\mathrm{C}$ groups (532.2-533.4 eV), and chemisorbed and adsorbed water $(534.6-535.4 \mathrm{eV})$. The $\mathrm{C}=\mathrm{O}$ contribution to the $\mathrm{O} 1 \mathrm{~s}$ profile increases significantly with increasing amount of electrochemical treatment.

As shown in Figure 1 and Table 4, a modest degree of electrochemical treatment improved the flexural modulus of the nanocomposite by enhancing the interfacial adhesion between the fiber and resin. The treatment time of 30 seconds allowed for a $4.32 \%$ increase in flexural modulus. A maximum improvement of $74 \%$ occurred with an electrochemical treatment time of twelve minutes. Prolonged subjection to the electrochemical treatment beyond eight minutes showed a drop in flexural modulus. This may be due to the oxide layer actually causing failure of the fiber-resin bond or possibly the additional treatment time may have damaged the fiber surface.

The electrochemical treatment did have a slightly negative effect on the thermal conductivity of the manufactured 
TABLE 4: Nanocomposite mechanical properties with relative standard deviation.

\begin{tabular}{lccccc}
\hline Sample & $\begin{array}{c}\text { Surface treatment } \\
\text { time (min) }\end{array}$ & $\begin{array}{c}\text { Mass } \\
\%\end{array}$ & $\begin{array}{c}\text { Modulus } \\
(\mathrm{GPa})\end{array}$ & STD & $\begin{array}{c}\text { Strength } \\
(\mathrm{GPa})\end{array}$ \\
\hline EPON 862 & - & 0 & 1.7730 & 0.0688 & 0.0976 \\
PR-24-PS & 0 & 12 & 2.5783 & 0.1267 & 0.1196 \\
PR-24-PS-ET (0.5) & 0.5 & 12 & 2.6898 & 0.5464 & 0.0901 \\
PR-24-PS-ET (1) & 1 & 12 & 2.7399 & 0.1619 & 0.1037 \\
PR-24-PS-ET (2) & 2 & 12 & 2.8014 & 0.1124 & 0.1072 \\
PR-24-PS-ET (4) & 4 & 12 & 3.0261 & 0.3434 & 0.1017 \\
PR-24-PS-ET (8) & 8 & 12 & 3.4915 & 0.0217 & 0.0057 \\
PR-24-PS-ET (10) & 10 & 12 & 3.9535 & 0.0118 & 0.01163 \\
PR-24-PS-ET (12) & 12 & 12 & 4.4856 & 0.0123 & 0.1263 \\
PR-24-PS-ET (15) & 15 & 12 & 3.0690 & 0.3558 & 0.1462 \\
\hline
\end{tabular}

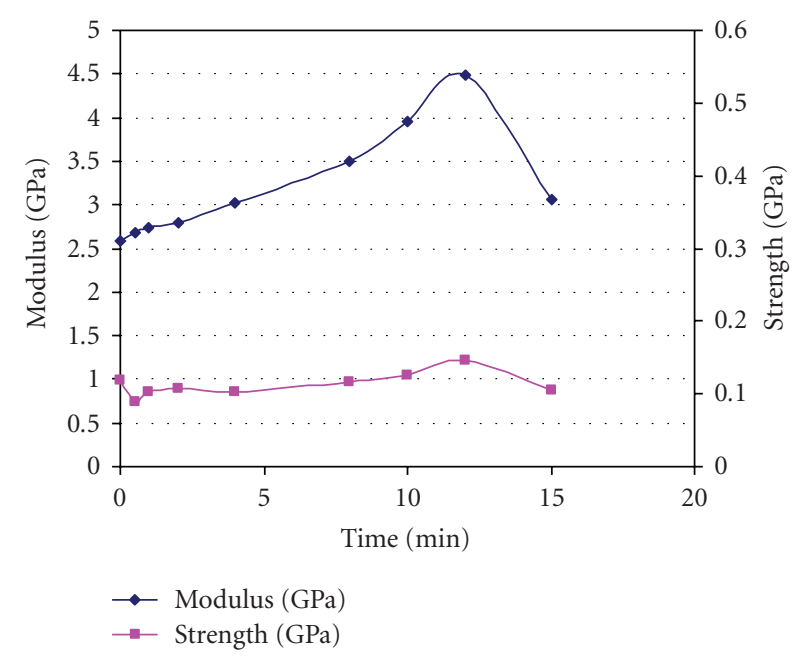

FIGURE 1: Nanocomposite mechanical properties as a function of electrochemical treatment time.

nanocomposites. As shown in Table 1, there was a significant decrease in the heat capacity of the composites with functionalized nanofibers, indicating an effect of additional oxygen content. There was not a significant change in the thermal diffusivity results. In addition, the electrical resistivity of the nanocomposites decreased with increasing electrochemical treatment time. This may be due to the increase in oxygen content causing the formation of a narrow insulating layer along the surface of the fibers (see Table 5).

The SEM examination of the fracture surface of various samples following mechanical testing has shown that the interface between the nanofiber and epoxy resin matrix has only minimal adhesion in the form of covalent bonds (Figures 2 and 3). An interfacial gap between the two phases is always present and its location may vary from one sample to another (single arrows in Figures 2 and 3).

The inability to create an effective interface between the carbon nanofiber and the neat resin prevents the transfer of mechanical loads between the two regions. This hindrance of load transference results in mechanical properties that are nominally better than those of the neat resin. To better understand the role of surface chemistry of the nanofiber, the

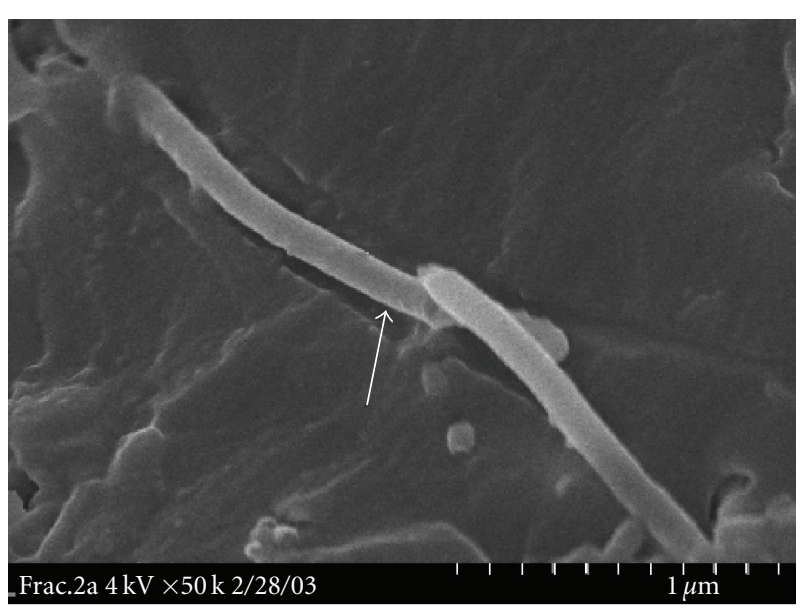

FIGURE 2: Longitudinal view of untreated nanofibers-based nanocomposite fracture surface.

effect of surface functionalization of nanofiber on the mechanical properties of produced nanocomposites was studied.

The fracture surface of the surface-functionalized nanocomposite is markedly different from that of the PR-24 nanocomposite. Along the length of the chemically modified nanofiber within the epoxy matrix, there is an apparent interface devoid of the gaps present in the pyrolytically stripped nanocomposite (see Figure 4). The body of the nanofiber is actually covered with lighter regions of "strings" and bumps arranged in the form of "knife teeth." These bumps are made of resin residue. This region is more closely studied using high-resolution SEM and TEM techniques.

In Figure 5, it is shown that the surface of the functionalized nanocomposite is covered with masses of residual epoxy resin. This demonstrates that the nanocomposite did not fracture along the nanofiber/resin interface. Rather, the resin remainent adhered to the nanofiber following fracture and the mechanical failure took place within the resin phase of the nanocomposite. TEM analysis offers a more thorough explanation for the interaction between the modified surface of the nanofiber and the epoxy resin. 
TABLE 5: Thermal and electrical properties of nanocomposites as a function of treatment time.

\begin{tabular}{|c|c|c|c|c|c|}
\hline Sample & $\begin{array}{l}\text { Surface treatment } \\
\text { time }(\mathrm{min})\end{array}$ & $\begin{array}{c}\text { Mass } \\
\% \\
\end{array}$ & $\begin{array}{l}\text { Resistivity } \\
(\mathrm{Ohm}-\mathrm{cm})\end{array}$ & $\begin{array}{c}\mathrm{K} \\
(\mathrm{W} / \mathrm{m}-\mathrm{K}) \\
\end{array}$ & $\begin{array}{l}\text { Density } \\
\left(\mathrm{g} / \mathrm{cm}^{3}\right)\end{array}$ \\
\hline EPON 862 & - & 0 & $3.28 \mathrm{E}+10$ & 0.1768 & 1.198 \\
\hline PR-24-PS & 0 & 12 & $1.58 \mathrm{E}+00$ & 0.3731 & 1.252 \\
\hline PR-24-PS-ET (0.5) & 0.5 & 12 & $4.13 \mathrm{E}+00$ & 0.2992 & 1.237 \\
\hline PR-24-PS-ET (1) & 1 & 12 & $5.16 \mathrm{E}+01$ & 0.3476 & 1.253 \\
\hline PR-24-PS-ET (2) & 2 & 12 & $3.14 \mathrm{E}+03$ & 0.3303 & 1.246 \\
\hline PR-24-PS-ET (4) & 4 & 12 & $5.57 \mathrm{E}+06$ & 0.3032 & 1.240 \\
\hline PR-24-PS-ET (8) & 8 & 12 & $3.35 \mathrm{E}+07$ & 0.3290 & 1.235 \\
\hline PR-24-PS-ET (10) & 10 & 12 & $5.56 \mathrm{E}+10$ & 0.3334 & 1.257 \\
\hline PR-24-PS-ET (12) & 12 & 12 & $4.54 \mathrm{E}+09$ & 0.3493 & 1.234 \\
\hline PR-24-PS-ET (15) & 15 & 12 & $3.69 \mathrm{E}+10$ & 0.3348 & 1.254 \\
\hline
\end{tabular}

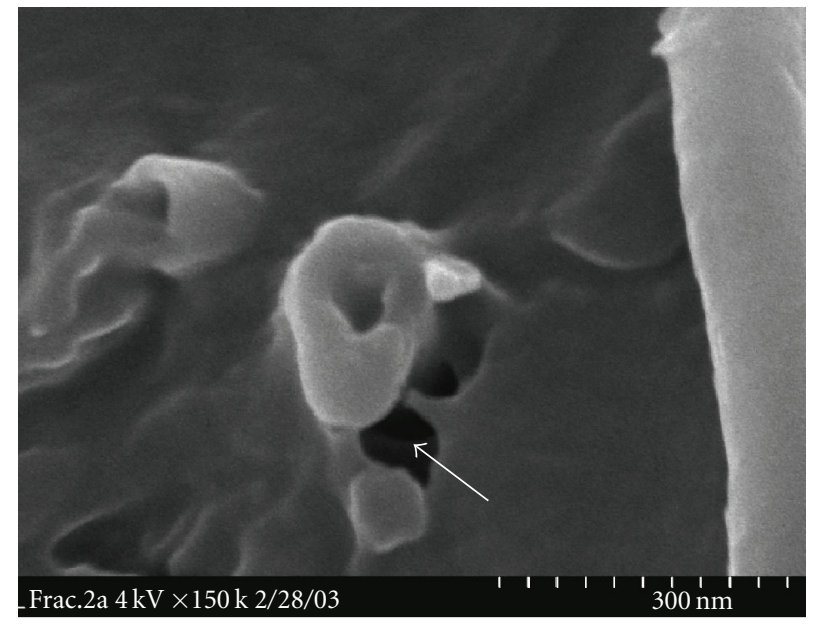

FIGURE 3: Cross view of untreated nanofibers-based nanocomposite fracture surface.

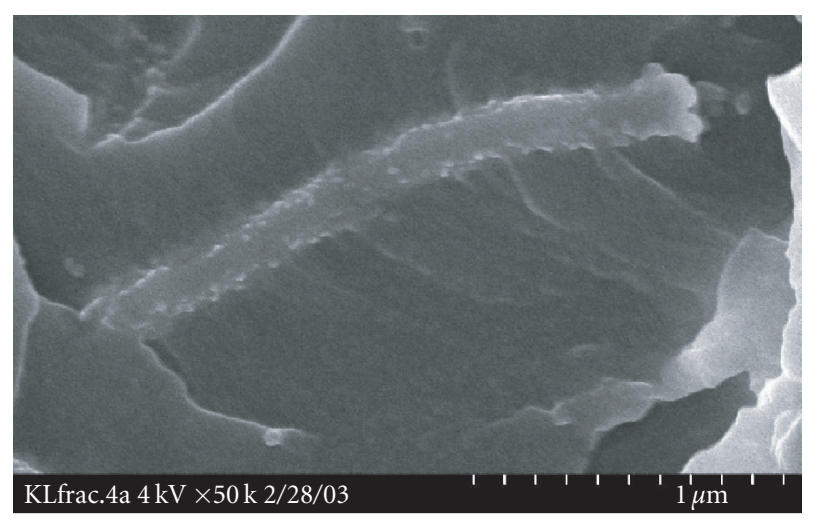

FIGURE 4: SEM micrograph of surface-functionalized nanocomposite fracture surface.

The black arrows in Figures 6 and 7 show the exposed ends of nanofibers and their bodies within the resin matrix at the fracture site. The bright-field micrograph shows a change in a grey scale to demonstrate differences in electronic density within the resin matrix. The epoxy resin areas do not

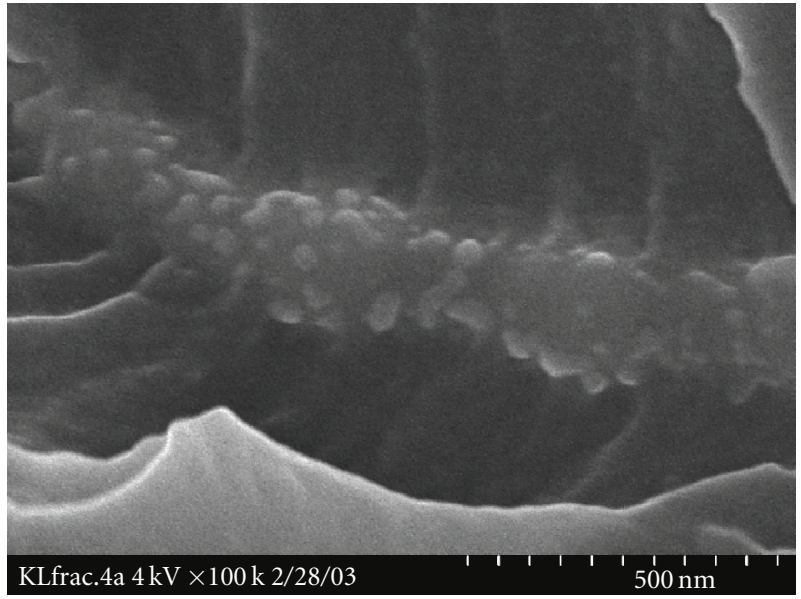

FIGURE 5: Higher magnification SEM of surface-functionalized nanocomposite fracture surface.

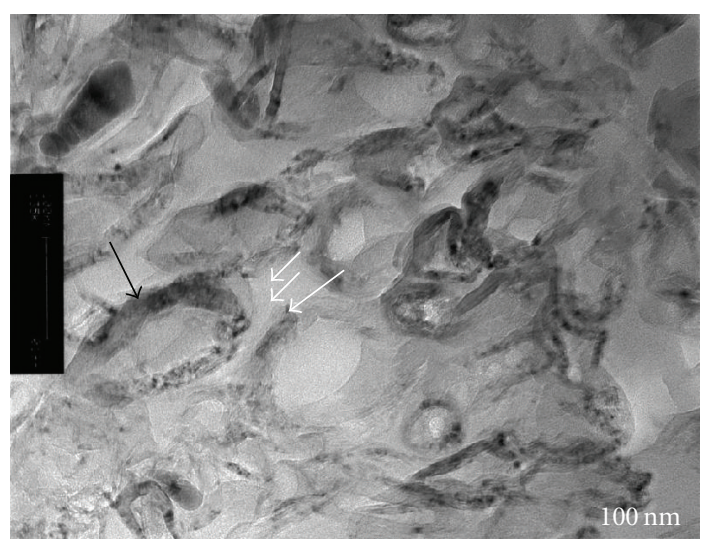

FIGURE 6: TEM micrograph of surface-functionalized transverse fracture surface.

have one consistent shade, however. The single white arrows in Figures 6 and 7 point to areas of higher electronic density than that of areas showing lighter contrast (double white arrows in Figures 6 and 7). This difference in a grey-scale may indicate some structural changes within continuous resin 


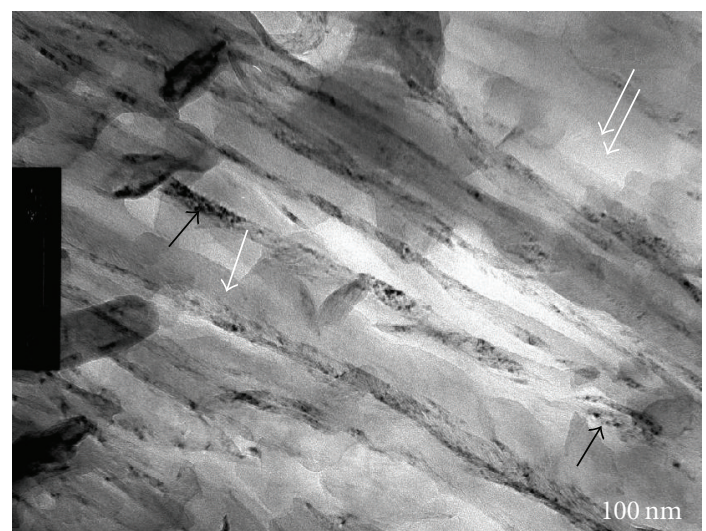

FIGURE 7: TEM micrograph of surface-functionalized longitudinal fracture surface.

matrix. A longitudinal representation offers a clearer understanding of the physical property gradient within the surfacefunctionalized carbon nanocomposite.

An analysis using high resolution TEM allows for a more complete understanding of the changes that occur at the interface between the surface-functionalized carbon nanofibers and the continuous epoxy resin phase.

At high resolution, the individual graphene planes of a nanofiber can be seen along with the region of the epoxy region. Moving from the upper-left towards the lowerright of the micrograph, the interface with the nanofiber is crossed into the parallel layers within the nanofiber representing the wall of nanofiber. Further down the micrograph, another interface is crossed into the epoxy resin phase with very organized turbostratic carbon (circled areas in Figure 8 with a wavy, spaghetti-like look). In this region, there is a local molecular orientation of basic structural units that are in the form of columns and clusters with discontinuous but preferential molecular orientation parallel to the nanofiber axis. The polymer interphase is no longer amorphous but has gained a two-dimensional order similar to the microstructure of carbonized PAN carbon fiber. Epoxy generally has gravel-like appearance under HR-TEM, which indicates an amorphous structure. This change in physical properties demonstrates the presence of an "interphase." Due to the chemical interaction between the surface-functionalized nanofiber and the resin, a new material has been created with unique physical properties.

\section{CONCLUSION}

In principle, achieving high tensile strength composites with nanofibers as the reinforcement relies on factors including weight fraction, strength of the nanofibers, dispersion of the fibers, and the strength of the interface. Assembly of these factors may be envisioned without difficulty; however, the latter factor-strength of the interfacial bond between nanofiber and matrix-is problematic due to the inert nature of the smooth hexagonal surface commonly presented by the nanofiber class of reinforcement.

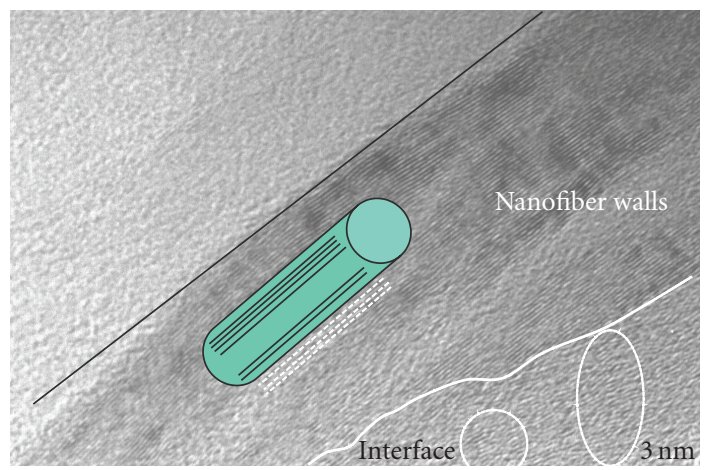

FIGURE 8: High resolution TEM showing an oriented interface between nanofiber and matrix.

Due to the exposed graphitic edge planes of nanofiber surfaces, it is possible to add functional groups. The addition of functional groups will greatly increase the ability of the nanofiber to bond to polar matrix materials such as epoxy. As a result of this surface modification, the mechanical properties of the nanocomposites were significantly enhanced, and the chemical properties such as heat capacity of the polymer were lowered. This improvement might be obtained by an internal reaction between the surface functional groups and polymer matrix. Transmission electron microscopy characterization shows that the post-synthesis surface treatment has contributed to the formation to a very dense and oriented interface between nanofiber and matrix.

The surface-treated nanofiber-based nanocomposites samples exhibit better mechanical properties than any of the nonsurface-treated nanofiber-based nanocomposites. The improvement in mechanical properties is due to the formation of gradients at interfaces and interphases between the nanofibers and epoxy resins. These interphases cause the polymeric nanocomposites to behave as a continuous phase in which the mechanical transport properties between parent individual ingredients (nanofibers and epoxy matrix) were enhanced.

There was a significant decrease in the relative content of graphitic carbon and an increase in the relative content of carbon bonded to oxygen-containing functions with increasing amount of electrochemical treatment. The increase in relative concentration of carbon oxygen complexes occurs because the outer layers of the fibers become increasingly porous allowing for additional sights of oxidation. The increasing amounts of oxygen with electrochemical treatment corresponded to an increase in the flexural modulus of nanocomposites manufactured with the treated fibers. This indicates an improvement in interfacial adhesion between the fibers and the resin. The treated nanofibers had negative impact on the heat capacity of the nanocomposites, but they did not affect the thermal diffusivity of the composites. The electrical resistivity of the nanocomposites decreased with increasing electrochemical treatment time due in part to the increased concentration of oxygen functional groups. 


\section{REFERENCES}

[1] V. Z. Mordkovich, "Carbon nanofibers: a new ultrahighstrength material for chemical technology," Theoretical Foundations of Chemical Engineering, vol. 37, no. 5, pp. 429-438, 2003.

[2] B. Maruyama and K. Alam, "Carbon nanotubes and nanofibers in composite materials," SAMPE Journal, vol. 38, no. 3, pp. 59-70, 2002.

[3] E. Lonzo and V. Barrera, "Nanofiber-reinforced thermoplastic composites. I. thermoanalytical and mechanical analyses," Journal of Applied Polymer Science, vol. 79, no. 1, pp. 125-133, 2000.

[4] R. J. Kuriger, M. K. Alam, D. P. Anderson, and R. L. Jacobsen, "Processing and characterization of aligned vapor grown carbon fiber reinforced polypropylene," Composites Part A, vol. 33, no. 1, pp. 53-62, 2002.

[5] R. D. Patton, C. U. Pittman Jr., L. Wang, and J. R. Hill, "Vapor grown carbon fiber composites with epoxy and poly (phenylene sulfide) matrices," Composites Part A, vol. 30, no. 9, pp. 1081-1091, 1999.

[6] S. Lim, S.-H. Yoon, I. Mochida, and J.-H. Chi, "Surface modification of carbon nanofiber with high degree of graphitization," Journal of Physical Chemistry B, vol. 108, no. 5, pp. 15331536, 2004.

[7] M. L. Toebes, J. M. P. van Heeswijk, J. H. Bitter, A. J. van Dillen, and K. P. de Jong, "The influence of oxidation on the texture and the number of oxygen-containing surface groups of carbon nanofibers," Carbon, vol. 42, no. 2, pp. 307-315, 2004.

[8] H. Bubert, X. Ai, S. Haiber, et al., "Basic analytical investigation of plasma-chemically modified carbon fibers," Spectrochimica Acta Part B, vol. 57, no. 10, pp. 1601-1610, 2002.

[9] J. Xu, J. P. Donohoe, and C. U. Pittman Jr., "Preparation, electrical and mechanical properties of vapor grown carbon fiber (VGCF)/vinyl ester composites," Composites Part A, vol. 35, no. 6, pp. 693-701, 2004.

[10] I. C. Finegan, G. G. Tibbetts, D. G. Glasgow, J.-M. Ting, and M. L. Lake, "Surface treatments for improving the mechanical properties of carbon nanofiber/thermoplastic composites," Journal of Materials Science, vol. 38, no. 16, pp. 3485-3490, 2003.

[11] P. Cortés, K. Lozano, E. V. Barrera, and J. Bonilla-Rios, "Effects of nanofiber treatments on the properties of vapor-grown carbon fiber reinforced polymer composites," Journal of Applied Polymer Science, vol. 89, no. 9, pp. 2527-2534, 2003.

[12] J. Harvey, C. Kozlowski, and P. M. A. Sherwood, "X-ray photoelectron spectroscopic studies of carbon fibre surfaces," Journal of Materials Science, vol. 22, no. 5, pp. 1585-1596, 1987.

[13] J. Gulyás, E. Földes, A. Lázár, and B. Pukánszky, “Electrochemical oxidation of carbon fibres: surface chemistry and adhesion," Composites Part A, vol. 32, no. 3-4, pp. 353-360, 2001.

[14] Z. R. Yue, W. Jiang, L. Wang, S. D. Gardner, and C. U. Pittman Jr., "Surface characterization of electrochemically oxidized carbon fibers," Carbon, vol. 37, no. 11, pp. 1785-1796, 1999. 

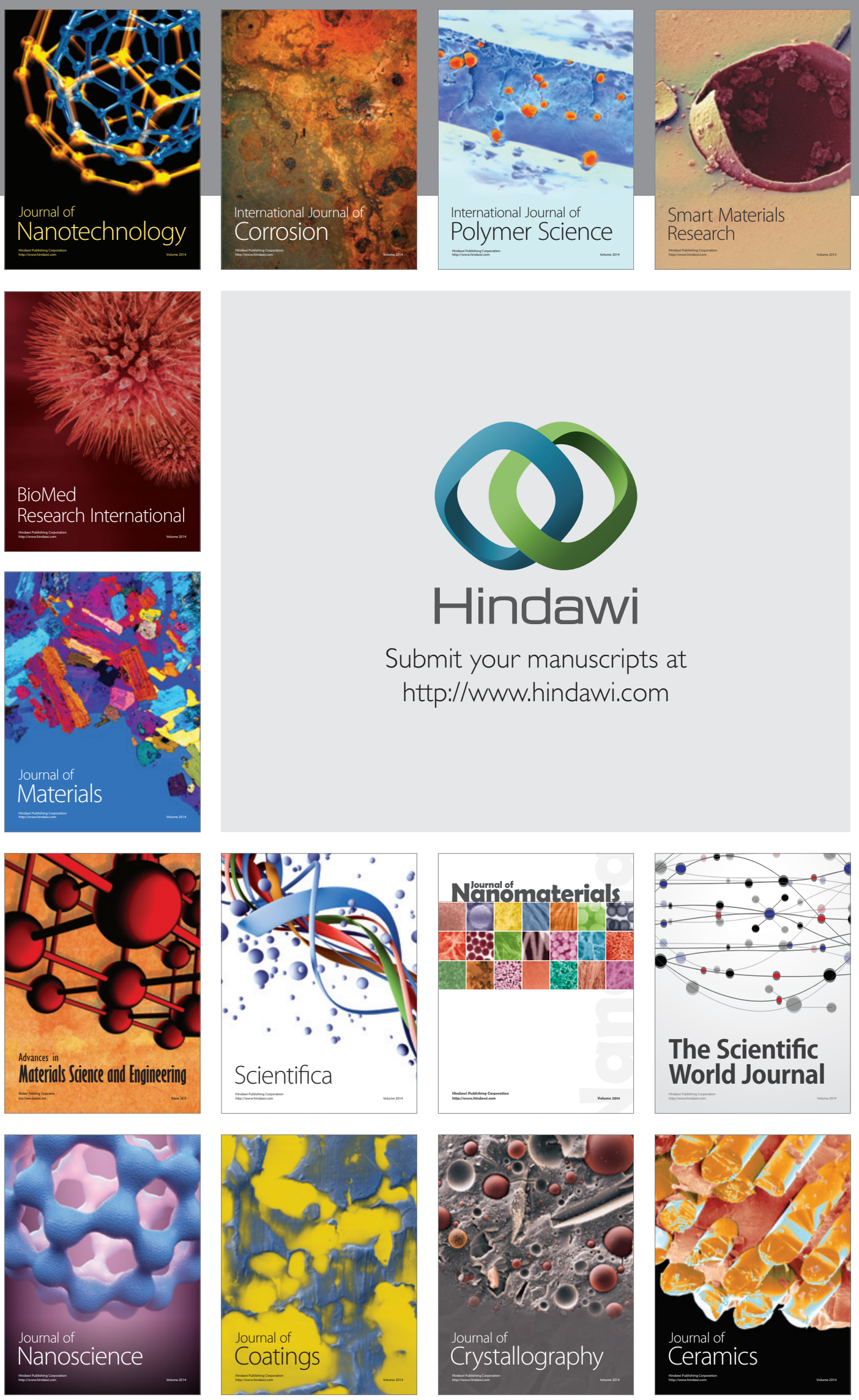

The Scientific World Journal

Submit your manuscripts at

http://www.hindawi.com

\section{World Journal}

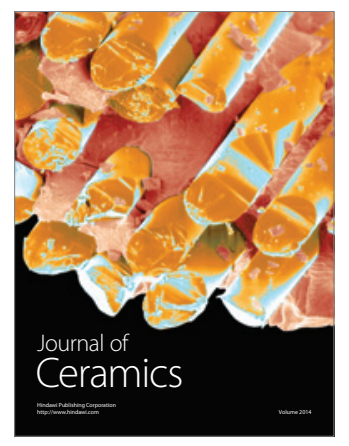

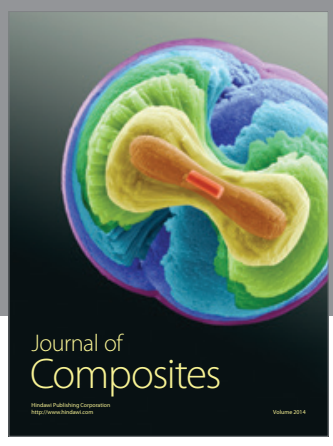
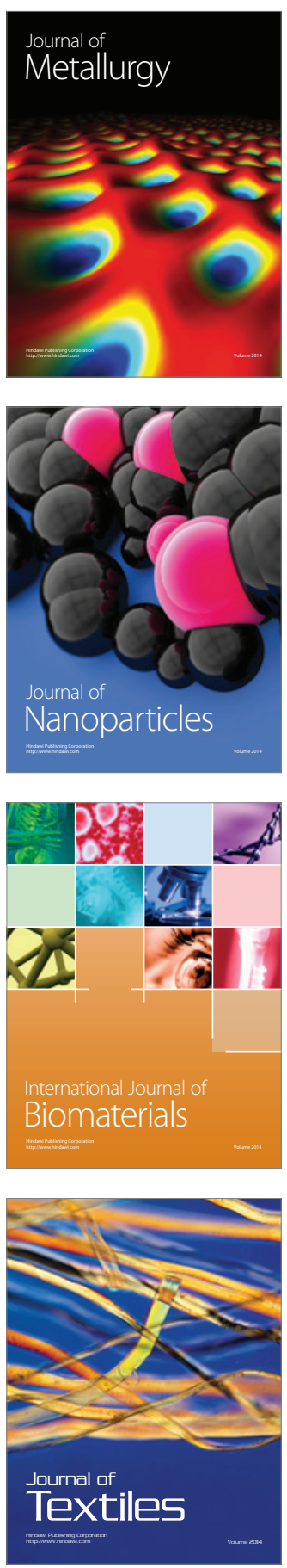